\title{
Management of Traumatic Spinal Fracture in Patient with Coronavirus Disease 2019 Situation
}

\author{
Dobran Mauro, Mancini Fabrizio, Iacoangeli Maurizio \\ Department of Neurosurgery, Umberto I General Hospital, Università Politecnica delle Marche, Ancona, Italy
}

To the Editor,

We read with great interest the article by Sornsa-Ard et al. [1]. This study described the management of traumatic spinal fracture in the pandemic coronavirus disease 2019 (COVID-19) and provided important insights into the management of traumatic spinal fractures in many hospitals with COVID-19 departments. We report the experience of the neurosurgical team working in the Emergency Regional Hospital of Ancona (Italy) which serves about 1.5 million inhabitants. Since pandemic COVID-19 spread in Italy last February 2020, our operating rooms have been split into two areas COVID-free rooms and COVIDrooms. All patients who required non-emergent surgery were treated in a COVID-free room only after a negative COVID swab test. On the contrary, patients who needed life-saving surgical procedures were operated in the COVID-19 room and hospitalized in a COVID-19 area waiting for swab response test. In traumatic spinal cord injury (SCI), the timing of the surgery is an important variable related to its neurological outcome. Despite the recent guidelines recommend to perform the surgical treatment within 24 hours for all SCI patients and many authors advocated a so called ultra-early surgery ( $<12$ hours) $[2,3]$, still today the optimal timeframe remain unknown. At our institution, the results of the COVID-19 swab test may be obtained in 4-6 hours. We believe that the best treatment for SCI patients is an early surgical treatment in a free-COVID room. Taking into account the time required for the swab results and the need of a COVID-19 negative test to enter in a COVID-free operative theater, nowadays our timeframe for an early surgical COVID-19 free treatment in SCI patients is decreased by $50 \%$ because, after the admission to hospital, 4-6 hours are lost for the COVID-19 test result. In this light the surgical decision became troublesome for patients admitted to our hospital after 8-10 hours from spinal trauma. Taking into account both the aim to avoid a COVID-19 pathway for patients without infection and the need to perform an early surgical procedure, we preferred waiting the swab result and treat patient at least within 12-24 hours from the spinal trauma. This choice is reinforced by the lack of class A guideline for SCI surgical timing [4,5]. An element in our favor for the fast surgical treatment is the Government lockdown measure started last March 2020 in Italy. This measure luckily reduced the incidence of traumatic SCI with a drop of about $60 \%$ of surgical procedures at our institution compared to the same period of 2019. This

Received Apr 30, 2020; Accepted Apr 30, 2020

Corresponding author: Dobran Mauro

Department of Neurosurgery, Umberto I General Hospital, Università Politecnica delle Marche, Via Tronto 10/A , Ancona, 60126, Italy

Tel: +39-3473626394, E-mail: dobran@libero.it 
made easier the management of SCI patients and general traumatic emergencies with lesser patients to treat surgically and faster diagnostic preoperative investigations. In conclusion, we agree that early surgery ( $<12$ hours) is the best choice for SCI patients [6], but at the current time, we believe that surgery within 24 hours may be a reasonable target since we need to get the swab test answer before start surgery for all patients.

\section{Conflict of Interest}

No potential conflict of interest relevant to this article was reported.

\section{References}

1. Sornsa-Ard T, Niramitsantiphong A, Liawrungrueang W. Management of traumatic spinal fracture in the coronavirus disease 2019 situation. Asian Spine J 2020 Apr 24 [Epub]. https://doi.org/10.31616/ asj.2019.0183.
2. Papadopoulos SM, Selden NR, Quint DJ, Patel N, Gillespie B, Grube S. Immediate spinal cord decompression for cervical spinal cord injury: feasibility and outcome. J Trauma 2002;52:323-32.

3. Newton D, England M, Doll H, Gardner BP. The case for early treatment of dislocations of the cervical spine with cord involvement sustained playing rugby. J Bone Joint Surg Br 2011;93:1646-52.

4. Ter Wengel PV, Feller RE, Stadhouder A, et al. Timing of surgery in traumatic spinal cord injury: a national, multidisciplinary survey. Eur Spine J 2018;27:1831-8.

5. El Tecle NE, Dahdaleh NS, Hitchon PW. Timing of surgery in spinal cord injury. Spine (Phila Pa 1976) 2016;41:E995-E1004.

6. Nasi D, Ruscelli P, Gladi M, Mancini F, Iacoangeli M, Dobran M. Ultra-early surgery in complete cervical spinal cord injury improves neurological recovery: a single-center retrospective study. Surg Neurol Int 2019;10:207. 